\title{
THE SURGICAL TREATMENT OF PRESSURE ULCERS IN THE PATIENT WITH SPINAL INJURIES
}

By

DR. J. A. ENGELBRECHT, MB, CH.,B., F.C.s. (s.A.)

Plastic Surgeon to the Cape Paraplegic Unit, Conradie Hospital

It was believed for many years that the healing powers in paraplegic patients was not the same as that in normal persons. This idea was especially propagated by Charcot, who postulated that there were so called, trophic centra, in the spinal cord. Injuries to the spinal cord cause damage to these trophic centra with resultant poor healing in these patients.

By careful observation and also clinical comparison, it has been proved that the healing power in the paraplegic patient is no different from that in a normal person, provided no pressure is allowed on the skin and subcutaneous tissue.

On the other hand, it must be remembered that venous congestion will interfere to a large extent with normal healing and may itself cause ulceration as we see for instance, in patients with varicose ulcers. These paralysed patients are far more liable to venous congestion in the paralysed limbs, because of their abnormal sympathetic and parasympathetic vascular control. This venous congestion in the paralysed limbs appears to be most severe during the first three months after injury, especially in cervical injuries. After that, the vascular tonus improves slowly, and the venous congestion of the skin diminishes.

The important factors in the prevention of pressure ulcers, both in the routine management and during the post-operative phase are therefore, regular turning of the patient, to prevent pressure, and active physiotherapy from an early stage of the paralysed limbs to improve the venous return. Movements of these limbs, plus deep breathing are of the greatest importance in helping the venous return.

Where pressure ulcers have developed it is important that they should be closed as soon as possible, because they are not only a constant source of infection, but are the cause of a tremendous and continuous loss of proteins by the patient. This is one of the reasons why these patients have great difficulty in maintaining a normal haemoglobin level. The presence of these infected ulcers also has a very poor psychological effect on the patients. It is often astonishing to see how the mental state improves after these ulcers have been closed. Where these ulcers have extended to the underlying bone, the chances that spontaneous and permanent healing will occur is remote. This applies particularly to the trochanteric and ischial regions, where although the ulcers often appear to be small on the surface, they are usually

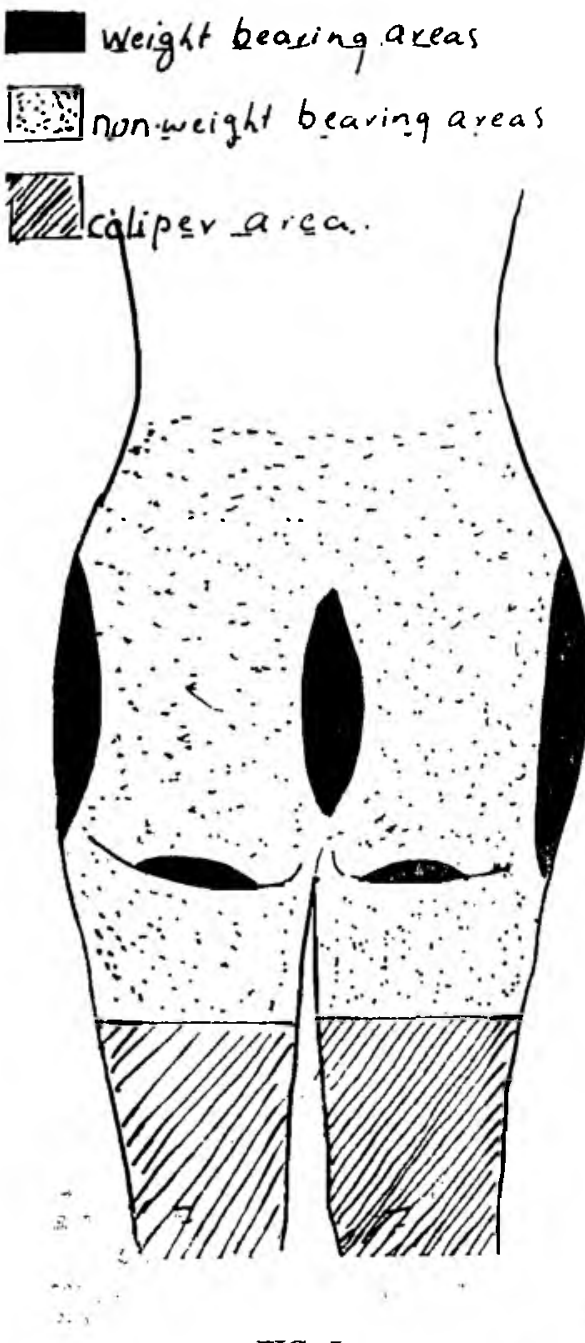

FIG. I

Shows the weight and non-weight bearing areas. 


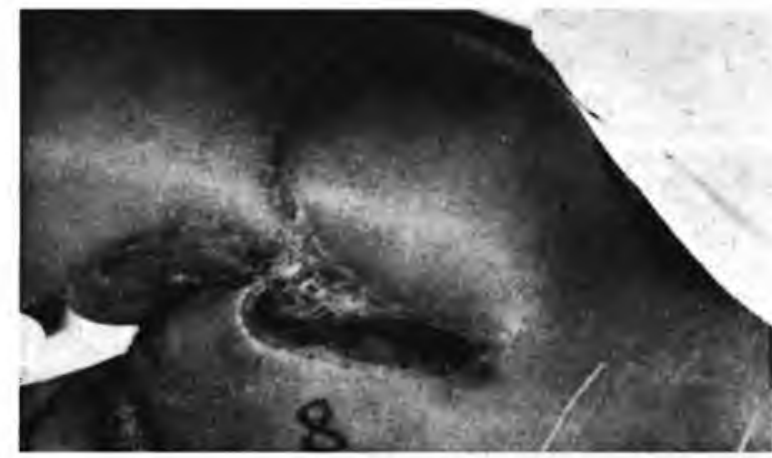

FIG. II

Ulcer over greater trochanter and tuber ischium after repair by flaps.

Note flaps in position and grafted donor areas over non-weight bearing flaps.

widely undermined with the bony prominence sitting in the opening like a cork in a bottle. This cork-like effect of the bony prominence blocks the opening of the bedsore and prevents drainage. This also results in the collection of infected serous fluid in the cavity with spread of the infection often to the underlying bone.

On more flat surfaces like the sacrum, the ulcer will usually heal after prolonged bed rest and dressings; but the area will be covered with a very thin fragile skin, which is adherent to the underlying bone. This paper-thin skin readily breaks down with the slightest trauma.

The best treatment for these pressure ulcers is excision and covering of the area with a full-thickness skin and subcutaneous fat flap. It is essential that the flap should be raised (see fig. 1) from an area which is non-weight bearing, and it must be placed in such a way that no suture lines cross the weight-bearing area.

Fortunately most of the pressure ulcers are seen in the gluteal region, where nature has been kind enough to provide the surgeon with some extra tissue, which can be used for flaps.

It is essential that the flaps should be raised from a nonweight bearing area, because the area from which the flap is raised is covered by a split thickness graft, which does not take weight-bearing well.

Where there is more than one ulcer, the area used should also be carefully selected to make the best use of the available areas to cover the ulcers.

The inner surface of these ulcers is always covered by a shiny fibrous layer, which must be fully excised to get the flap to adhere. It is also necessary to remove as much as possible of the underlying bony prominence before the flap is surtured into place in order to lower the pressure point as well as to remove all the infected bone. The tuber ischium can be totally removed while the spines of the sacrum and the greater trochanter can be trimmed well down.
The biggest cause of failure in this method of closure of ulcers is the formation of a haematoma beneath the flap. It must be remembered that because of their poor vascular control, these patients tend to bleed more and for a longer period after surgery than normal persons. There is also always a potential cavity underneath the flap until such time as it becomes adherent to the underlying bone. We therefore use a thin portex tube for drainage which is connected to a Stedmans pump. This drain is left in for 12 to 14 days with continuous suction at two atmospheres pressure.

During the first two post-operative weeks it is necessary that the patient be nursed in such a way that no pressure is allowed on the flap, but it is essential that as much physiotherapy as possible should be given.

Severe muscle spasm during the post-operative period can be very tourblesome, because it can be the cause of tension at intervals on the suture line. Where severe spasm is a threat to good healing of the suture line, an intrathecal alcohol or phenol block may have to be considered. Since this procedure is only permissible in cases who have a severely crippled bladder, prior consultation with the urologist is essential.

Where no complications have developed, it is possible to get the patient out of bed three weeks after the operation. In the hands of an experienced plastic surgeon, the complications should be minimal and very few flaps should fail.

\section{A. C. MILLER \& CO. ORTHOPAEDIC MECHANICIANS}

Manufacturers and Suppliers of:

ORTHOPAEDIC APPLIANCES, ARTIFICIAL LIMBS, TRUSSES, SURGICAL CORSETS, URINALS, ARCH SUPPORTS, COLOSTOMY BELTS, ELASTIC STOCKINGS, ANKLE GUARDS, WRIST GUARDS, ELBOW GUARDS, KNEE GUARDS, LIGHT DURAL CRUTCHES FOR CHILDREN, WOODEN CRUTCHES, AND METAL ELBOW CRUTCHES.

Phone 23-2496 P.O. Box 3412 312 Bree Street, Johannesburg 